\title{
Lineament Length and Density Analyses Based on the Segment Tracing Algorithm: A Case Study of the Gaosong Field in Gejiu Tin Mine, China
}

\author{
Chunzhong Ni, ${ }^{1}$ Shitao Zhang, ${ }^{1}$ Chunxue Liu, ${ }^{2}$ Yongfeng Yan, ${ }^{1}$ and Yujian Li \\ ${ }^{1}$ Faculty of Land Resource Engineering, Kunming University of Science and Technology, Kunming 650003, China \\ ${ }^{2}$ School of Urban and Environment, Yunnan University of Finance and Economics, Kunming 650221, China \\ Correspondence should be addressed to Chunzhong Ni; 281262717@qq.com
}

Received 27 March 2016; Accepted 7 September 2016

Academic Editor: Francesco Soldovieri

Copyright (C) 2016 Chunzhong Ni et al. This is an open access article distributed under the Creative Commons Attribution License, which permits unrestricted use, distribution, and reproduction in any medium, provided the original work is properly cited.

\begin{abstract}
This study used the Segment Tracing Algorithm (STA) to extract lineaments from remotely sensed images. A computer program was then written to calculate the lineament densities and lengths. In Gaosong field, 3,233 lineaments were extracted based on a $200 \mathrm{~m} \times$ $200 \mathrm{~m}$ grid size. The results indicate that most lineaments lengths are between $30 \mathrm{~m}$ and $50 \mathrm{~m}$, and the number of lineaments within each cell ranges from 1 to 6 . Areas with high distributions exist on both sides of the central region. According to the contour map of lineament length, the maximum lineament length is $380 \mathrm{~m}$, and the minimum length is $30 \mathrm{~m}$. The contours mainly extend in two directions, including NE and NW trends. This is consistent with the prominent NE and NW strike faults that prevail in the mining area. The results are similar to those obtained in the Machishui ore block, which has become a mine production area. High values of lineament length and density in the contour map of Gaosong field may be associated with hydrothermal tin mineralization in the study area. The results of this study potentially provide a new approach to mineral exploration in the early stage of geological prospecting.
\end{abstract}

\section{Introduction}

Lineaments are straight or approximately linear landforms that are widely distributed across the surface of the Earth and are closely related to underground concealed faults. Lineaments are related to fractures and faults in slightly inclined stratigraphic regions. The direction and number of lineaments reflect rock mass fracture patterns and can provide valuable information related to geological structures, tectonics, hazard assessment, and natural resource availability [1-5]. Remote sensing images cover specific intervals of electromagnetic spectrum wavelengths and therefore contain more information than traditional aerial images. Remote sensing images can illustrate various types of lineaments with different structural characteristics and tectonic activities. Lineaments can be extracted from remote sensing images via computer software. This lineament extraction process identifies various lineament parameters, including the beginning and endpoint coordinates, direction, and length.
Several researchers have conducted lineament length and density studies [2, 6-8]. Many of these studies utilized technology and computer programs to analyze length and density data. The segment tracing and rotation transformation approach can be used to produce lineaments density diagrams; for example, a density diagram was produced in southwest Japan by extracting lineaments from satellite images using the discrete element method (DEM) $[6,9]$. Zeeb et al. [10] presented a fracture network evaluation program (FraNEP) to analyze lineament density, intensity, and mean length via scanline sampling and window sampling, or the circular scanline and window method. The FracSim 3D software package, which includes histogram analysis and probability plot tools, is designed to analyze the generated fracture lengths [11]. The LINDENS program has been used to estimate lineament densities in the Neogene Duero Basin in Northern Spain [2]. Markovaara-Koivisto and Laine wrote a Matlab script to model the lengths and densities of lineament 
tunnel fractures using field data [12]. However, most of these methods are based on traditional lineament interpretations, which set the cell size and use statistical methods to obtain the lineament position, length, and other parameters.

Numerous hydrothermal deposits that are associated with lineament distributions have been studied on different scales [13-16]. Many geologists believe that temporal and spatial distributions of ore deposits are not coincidental, and the relationship between lineaments and ore deposits has attracted significant interest [17, 18].

Gaosong is one of the main tin deposits in Gejiu District, and the fracture structure of Gaosong deposit is very complex $[19,20]$. The formation of the hydrothermal ore deposit, which is associated with magmatic-hydrothermal fluids, was the result of fluids generated in the Earth's crust migrating from low-permeability to high-permeability zones via the fracture structure, which includes lineaments near the surface. Most lineament research has focused on structural measurements [21, 22], tectonic and geochemical evaluations $[23,24]$, determination of the fault and ore body directions [20], and fracture structure characteristics that are linked to multiperiodic activity [25]. However, few lineament length and density studies have been conducted.

In this study, lineaments were extracted from remotely sensed images of Gaosong ore field. First, the linear relationship between the structures and the unit grid was determined. Then, a program was developed to analyze the lineament lengths and densities. The lineament lengths and number of lineaments in each grid were then presented as a contour map. The results provide significant advances in the field of ore body exploration.

\section{Geology of Gaosong Ore Field}

Gaosong ore field is located in the northeastern Gejiu tin ore deposit and the northern Wuzishan anticlinorium. The field is sandwiched between the NS Gejiu fault, the EW Jiajieshan fracture bed, and the EW Gesong and Beiyinshan faults. Therefore, the geological setting of the ore deposit is complex. Mesozoic, Permian, and Triassic strata mainly outcrop in the Gaosong ore field and comprise dolomite and dolomitic limestone. Tertiary mudstone, quaternary residual, and slope deposits are fragmentarily distributed in the area $[19,21]$.

The fold structure consists of the nearly EW striking Duimen Mountain-Axi Village syncline and the NNW Hump Mountain anticline. The fracture structure can be divided into EW, NE, NW, and SN groups based on strike. The major fault strike directions are EW and NE, and NW strikes are also fairly common. The EW fracture group contains the Gesong fault, the Kirin Mountain fault, the Machishui fracture, the Gaoa fracture, and the Beiyin Mountain fault from north to south. These features are near-equally distributed. The Gesong and Beiyin Mountain fault scales are the largest, and the Kirin Mountain fault is the third largest. The NE fracture set includes the Lotus Flower Mountain, Lutangba, and Linaxi fractures from west to east. The NW fracture set includes Daqingdong, Heimashi, Camel, Axi Village, and Lina fractures. The NS fracture set is not developed within the ore field (Figure 1).

\section{Lineament Extraction}

Lineaments were extracted using the Segment Tracing Algorithm (STA) [4], which searches for the digital number (DN) in each pixel of a satellite image. Each pixel ridge and valley can be determined based on continuous or discontinuous $\mathrm{DN}$ values. The image must be preprocessed before the lineaments can be extracted. The median filtering method is used to smooth the image and eliminate noise [26]. The STA method includes the following procedures.

3.1. Search for Pixels in a Continuous Direction. First, a small window is established with a pixel at the center. The window size is either $5 \times 5,9 \times 9$, or $11 \times 11$ pixels, and several (such as 16) radial search direction intervals are set over the range of 0 to $\pi$ (Figure 2).

The variable $z(x)$ represents the DN value of pixel $x$, and $z(x+h)$ represents the DN value of a distance $x$ and an angle $\theta$. The continuity of the $\mathrm{DN}$ value based on a straight line can be evaluated using

$$
\varepsilon(x)=\int_{-a}^{a} w(x+h)\{z(x)-z(x+h)\}^{2} d h,
$$

where $w(x)$ represents pixel $x$, corresponding to the weight coefficient; $h$ is the distance from $x$; and $a$ is the distance from the object of interest. The weight coefficient $w(x)$ strengthens the role of pixel $x$ and emphasizes the difference between pixels that are close to $x$ and the DN values of the pixels.

When $\varepsilon$ is small, the direction $\left(k_{\min }\right)$ can be used as a continuity direction for the DN pixel values. Lineaments can be extracted using the DN pixel data, which might require the use of a larger window. This study considers the lineament search precision and elapsed search time based on an $11 \times 11$ pixel window size.

3.2. Line Element Determination. The rate of change of $z(x)$ is calculated using (2); the rates of change are equally important in bright and dark areas; hence,

$$
\lambda=\frac{\left\{d^{2} z(x) / d x^{2}\right\}^{2}}{z(x)} .
$$

Given that the DN pixel values occur in a rectangular direction $\left(k_{\max }\right)$, (3) can be formulated as follows:

$$
\Lambda=\sum_{i=-4}^{4} \lambda_{i}=\sum_{i=-4}^{4} \frac{\left(z_{i+1}-2 z_{i}+z_{i-1}\right)^{2}}{z_{i}} .
$$

If $\lambda_{0}$ is greater than the threshold value $T$, then the center pixel is considered a line element $p$ :

$$
T=\nu+\mu \sigma, \quad \mu=\frac{\phi_{1}}{1+(\eta-1) \sin \theta} .
$$

In (4), $\nu$ and $\sigma$ represent the mean and standard deviation, respectively. $\eta$ is the ratio of $\gamma(h)$ that corresponds to the adjacent pixels $(h=1)$ and their DN values, where $\eta=\gamma_{p}(1) /$ $\gamma_{c}(1)$. The value of $\eta$ can be determined using the $\mathrm{DN}$ variation function $\gamma(h) . \gamma(h)$ represents the relationship between 

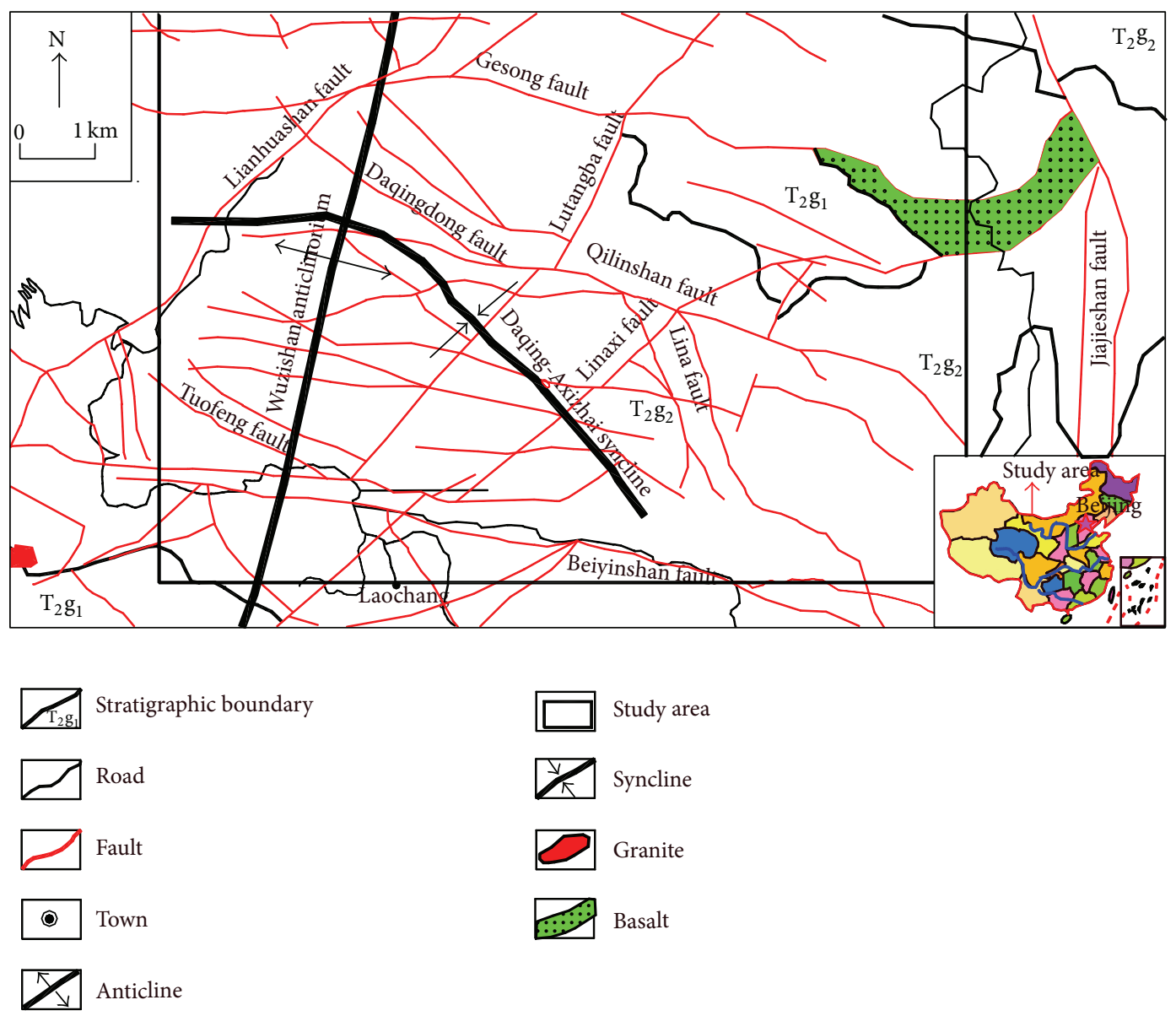

Figure 1: Geology map of Gaosong field in Gejiu Tin Mine (modified from Zhuang et al. [19]). $\mathrm{T}_{2} \mathrm{~g}_{1}$ : dolomite and limestone in the Kafang member of Gejiu formation in the middle Triassic; $\mathrm{T}_{2} \mathrm{~g}_{2}$ : dolomite in the Malage member of Gejiu formation in the middle Triassic; $\mathrm{T}_{2} \mathrm{~g}_{3}$ : limestone in the Bainidong member of Gejiu formation in the middle Triassic.

\begin{tabular}{|c|c|c|c|c|c|c|c|c|c|c|}
\hline 5 & 4 & 4 & 3 & 2 & 1 & 16 & 15 & 14 & 14 & 13 \\
\hline 6 & 5 & 4 & 3 & 2 & 1 & 16 & 15 & 14 & 13 & 12 \\
\hline 6 & 6 & 5 & 4 & 3 & 1 & 15 & 14 & 13 & 12 & 12 \\
\hline 7 & 7 & 6 & 5 & 3 & 1 & 15 & 13 & 12 & 11 & 11 \\
\hline 8 & 8 & 7 & 7 & 5 & 1 & 13 & 11 & 11 & 10 & 10 \\
\hline 9 & 9 & 9 & 9 & 9 & 0 & 9 & 9 & 9 & 9 & 9 \\
\hline 10 & 10 & 11 & 11 & 13 & 1 & 5 & 7 & 7 & 8 & 8 \\
\hline 11 & 11 & 12 & 13 & 15 & 1 & 3 & 5 & 6 & 7 & 7 \\
\hline 12 & 12 & 13 & 14 & 15 & 1 & 3 & 4 & 5 & 6 & 6 \\
\hline 12 & 13 & 14 & 15 & 16 & 1 & 2 & 3 & 4 & 5 & 6 \\
\hline 13 & 14 & 14 & 15 & 16 & 1 & 2 & 3 & 4 & 4 & 6 \\
\hline
\end{tabular}

FIgURE 2: Sixteen data-searching processes. distance $h$ and the variance of each data pair. The equation used to determine $\gamma(h)$ is $\gamma(h)=E\left[\{z(x+h)-z(x)\}^{2}\right] / 2$, where $E$ represents the expectation. Variation functions are created parallel and perpendicular to the sun direction $(s)$ and are denoted by $\gamma_{p}(h)$ and $\gamma_{c}(h)$, respectively.

3.3. Line Element Connection. The connection direction of line element $p$ is limited to the range of $k_{\min }-\pi / 16 \sim$ $k_{\min }+\pi / 16$ along $k_{\min }$. The sector scan area consists of $p$, $k_{\text {min }}, H$, and the apex angle, where $p$ is the center pixel, $k_{\text {min }}$ is the center direction, $H$ is the radius, and the apex angle is equal to $\pi / 8$. If multiple line elements exist, then $p$ and the line element farthest from $p$ should be connected within the search area:

$$
H=\frac{\phi_{2}}{1+(\eta-1) \cos \theta}+\phi_{3},
$$

where $H$ is related to the line element azimuth.

Each pixel in the study area can be searched, evaluated, and connected using the above steps. The lineaments characteristics in a remote sensing image can then be calculated. 


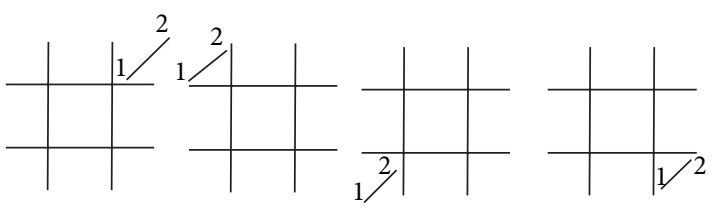

(a)
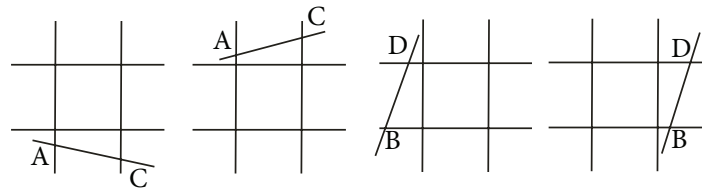

(b)

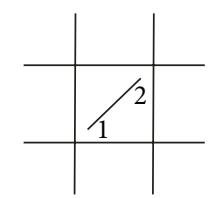

(c)

FIgURE 3: Three types of line segments and square intersections.

\section{Lineament Density and Length Calculations}

The simplest method of determining the linear density involves the following steps: dividing the study area into several square grids, determining whether lineament start or endpoints fall within each square grid, counting the number of lineaments, and summing the segment lengths in each grid.

Lineaments are divided into three types based on the relationship between the lineament distribution and square grid intersections. We assume that $x_{1}, y_{1}$ and $x_{2}, y_{2}$ are the beginnings and ends of the lineaments, respectively; the left and right grid coordinates are $x_{l}$ and $x_{r}$, respectively; and the upper and lower grid coordinates are $y_{u}$ and $y_{d}$, respectively. Three scenarios are identified as follows:

(1) The line segment-square relationships are classified as follows: (A) the line is located completely outside the square (Figure 3(a)), (B) most of the line is located outside the square (Figure $3(\mathrm{~b})$ ), or $(\mathrm{C})$ the line is completely within the square (Figure 3(c)).

(2) The line segment start and endpoints are located outside the square, but the line cuts across the square (Figure 4).

(3) One line endpoint is located inside the square (Figure 5).

Instances of scenario (1) are identified first. Scenarios (2) and (3) are identified based on the relationship between the lineaments and the square (A, B, C, and D in Figure 5).

Lineament lengths are different for different distribution types. For lines located completely within a square (Figure 5(C)), lineament length is based on the entire length within the square. However, scenario (2) only measures the length within the grid lines, and scenario (3) measures the distance between the lineament-square intersection and the endpoint inside the square.
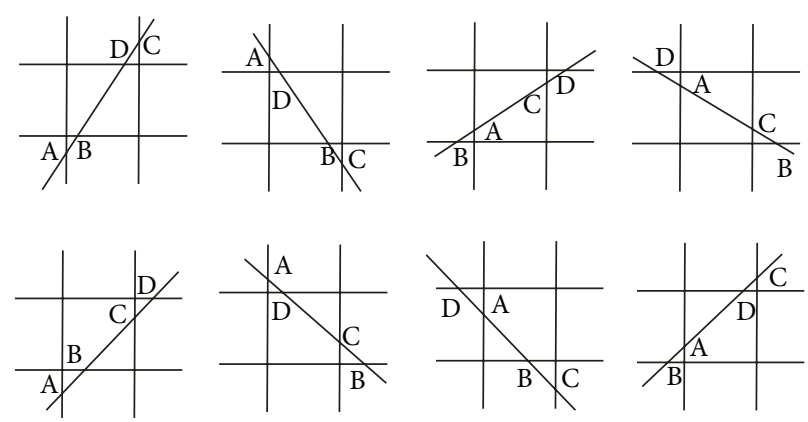

FIGURE 4: Various combinations of line segments and square intersections.
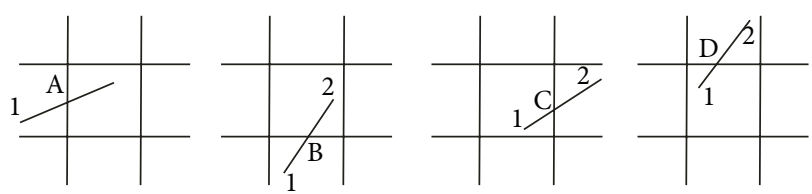

FIGURE 5: Line segments with only one endpoint within the grid.

\section{Results and Discussion}

A Matlab computer program was developed to calculate lineament length based on the methods presented in the previous sections. A total of 3,233 lineaments were extracted from an ETM+ image covering the Gaofengshan-Songshujiao region (Figure 6(a)), which was acquired on February 28, 2003, with less than $5.7 \%$ cloud cover. The orbit number is $\mathrm{p} 129 / \mathrm{r} 44$. The image has a resolution of $30 \mathrm{~m}$. The start and end coordinates of the lineaments were used as inputs to determine the lineament types. The measured lineament lengths and densities were then compared with measured faults [25].

The largest extracted lineament length was $400 \mathrm{~m}$, and the smallest was $30 \mathrm{~m}$. A histogram showing the lineament length distribution is presented in Figure 7, which illustrates that most (60.9\%) lineament lengths are between $30 \mathrm{~m}$ and $50 \mathrm{~m}$.

These results were used to produce a $50 \times 35$ cell grid covering a $200 \mathrm{~m}$ by $200 \mathrm{~m}$ area. A contour map was then created based on the number of lineaments and the lineament lengths in each cell, as shown in Figures 6(b) and 6(c).

Several conclusions can be drawn based on the lineament contour maps. Generally, (1) to (6) lineaments occur in each cell, and the cells with the highest numbers are distributed near the central area where Lutangba, Daqingdong, and Gaofengshan ore blocks are located. These high values are associated with the Machishui fault and the Daqingdong fault, and the Daqingnanshan fault bisects the region containing high numbers of fractures. The east-central region containing high numbers of lineaments is located near the junction of Qilinshan, Axizhai, and Lina faults. These areas with high numbers of lineaments coincide with the available surface information. Regions with high lineament lengths are mainly located near the center of the ore field; these lineaments exhibit a maximum length of $380 \mathrm{~m}$ and a minimum 

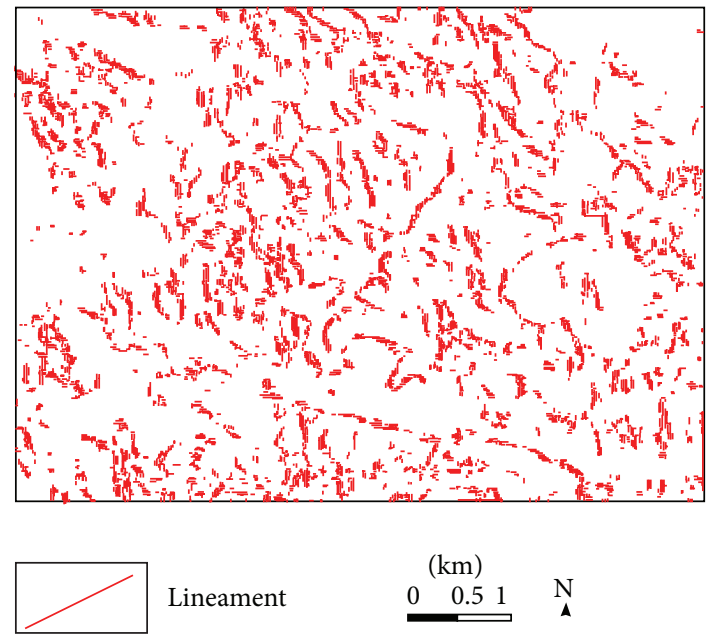

(a)
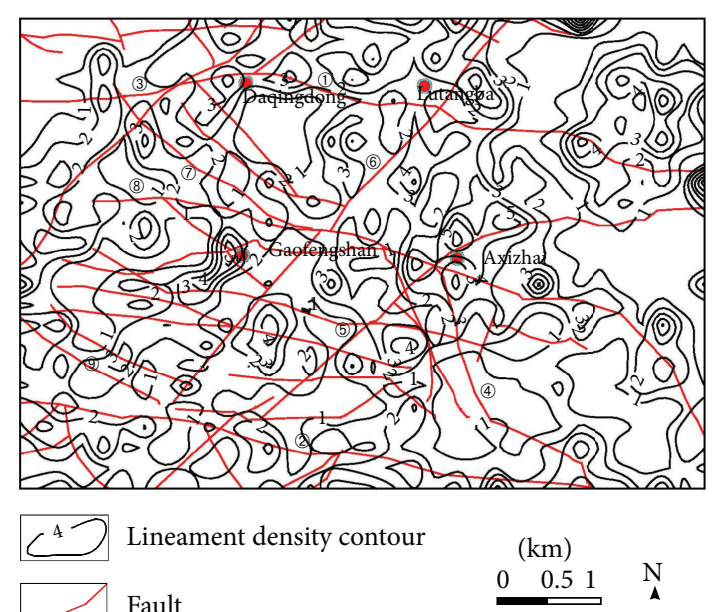

Fault

Ore block

(b)

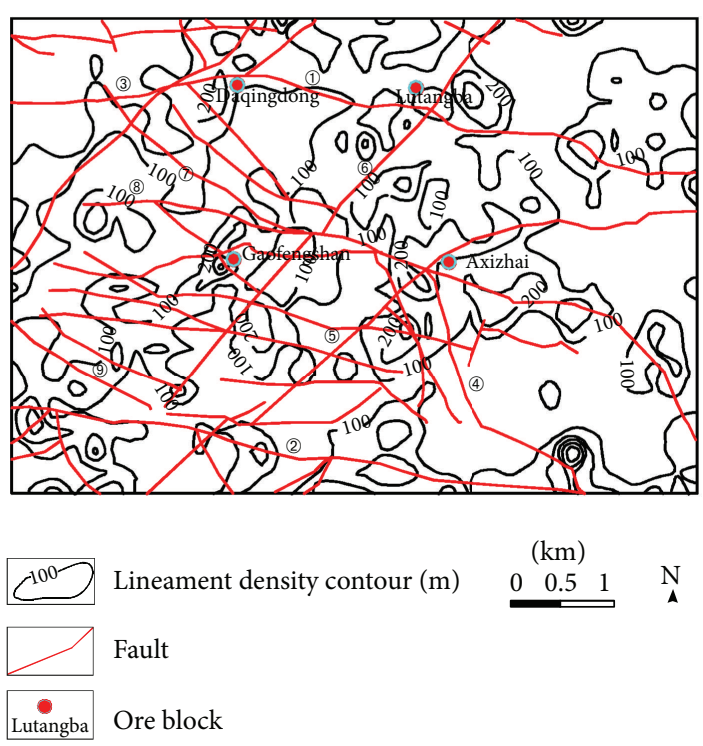

(c)

FiguRE 6: (a) Lineament interpretation results. (b) Lineament number contour map. (c) Lineament length contour map. (1) Gesong fault; (2) Beiyinshan fault; (3) Lianhuashan fault; (4) Lina fault; (5) Linaxi fault; (6) Lutangba fault; (7) Daqingdong fault; (8) Qilinshan fault; and (9) Tuofeng fault.

length of $30 \mathrm{~m}$, and most lineaments are between $30 \mathrm{~m}$ and $50 \mathrm{~m}$. The contour maps show that areas with high lineament lengths are present across the study area, suggesting broad fracture development. Lineaments that are longer than $200 \mathrm{~m}$ are mainly distributed in the center of the ore field but are also scattered in the northern portion of the field. Lineaments are typically aligned NE or NW, a finding that is consistent with the major faults in the area. Large lineaments have developed at the intersection of Axizhai and Qilinshan faults. The contour mapping results are similar to those obtained in the mine production area of Machishui fault, suggesting that the area might possess significant mining potential.
Koike et al. [6] extracted lineaments from satellite images and DEMs of southwestern Japan to create maps of lineament length density by counting line element pixels in a small window. Therefore, their results reflected the center pixel of an 11-by-11 pixel window. The lineament lengths calculated in this study are based on the relationships between line segments and a grid, which might reduce the required processing time. Casas et al. used the Delauney triangulation method to determine the distance between lineaments in the Neogene Duero Basin (approximately $150 \mathrm{~km} \times 250 \mathrm{~km}$ ), which is larger than our study area [2]. They used different mesh sizes to analyze the linear structure of the basin, and 


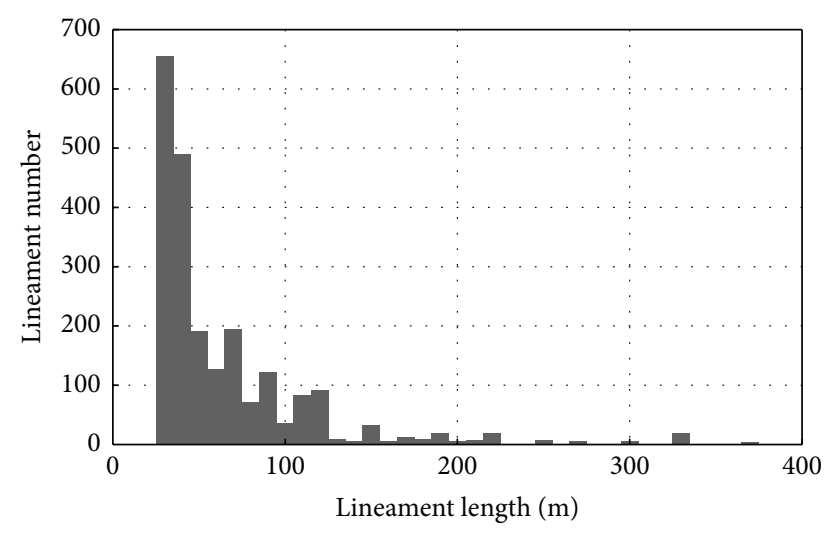

FIGURE 7: Histogram of lineament length distributions.

the results suggested that the number of zero values increases as the mesh size decreases.

\section{Conclusions}

This study used the STA to extract lineaments. The lineament densities and lengths were then calculated using a Matlab program, and the results were plotted as contour diagrams. These diagrams indicate that the maximum lineament length is $380 \mathrm{~m}$, the minimum length is $30 \mathrm{~m}$, and most lengths lie in the range between $30 \mathrm{~m}$ and $50 \mathrm{~m}$. Eighty percent of all lineaments were included in the grid. Lineament lengths greater than $200 \mathrm{~m}$ were mainly distributed in the central portion of the ore field. Each grid cell typically contained 1 to 6 lineaments, and the most densely fractured regions were located near the center of the field.

Gaosong ore deposit has experienced Yanshannian (Mesozoic) tectonic movements, creating a complex geological structure. This study successfully used the STA method to extract the lineament characteristics of the area for the first time.

Lineaments are closely related to mineralization; therefore, studies of lineament distribution features that might control ore fluid migration are warranted. Most previous linear structure studies were based on field data, geophysical data, or data that were manually extracted from satellite images. These methods require significant time and entail significant artificial errors. However, the proposed method can effectively avoid these shortcomings.

Because lineaments are closely connected to the formation of hydrothermal ore deposits, lineament characteristics can potentially be used to identify new exploration areas.

\section{Competing Interests}

The authors declare no competing interests regarding the publication of this paper.

\section{Acknowledgments}

Financial support for this study was provided by the Basic Research Project (no. 2013FZ026) of Yunnan Province and the Project $(41562017,40902058)$ supported by NSFC. Many thanks are due to Mr. Wenjie Zhu, Mr. Deming Kang, Mr. Rongyu Lu, and other geoworkers from the Yunnan Tin Group for their assistance during the field work.

\section{References}

[1] T. C. Ekneligoda and H. Henkel, "Interactive spatial analysis of lineaments," Journal of Computers and Geosciences, vol. 36, no. 8, pp. 1081-1090, 2010.

[2] A. M. Casas, A. L. Cortés, A. Maestro, M. A. Soriano, A. Riaguas, and J. Bernal, "LINDENS: a program for lineament length and density analysis," Computers and Geosciences, vol. 26, no. 9-10, pp. 1011-1022, 2000.

[3] A. A. Masoud and K. Koike, "Morphotectonics inferred from the analysis of topographic lineaments auto-detected from DEMs: application and validation for the Sinai Peninsula, Egypt," Tectonophysics, vol. 510, no. 3-4, pp. 291-308, 2011.

[4] A. A. Masoud and K. Koike, "Auto-detection and integration of tectonically significant lineaments from SRTM DEM and remotely-sensed geophysical data," ISPRS Journal of Photogrammetry and Remote Sensing, vol. 66, no. 6, pp. 818-832, 2011.

[5] K. Koike and Y. Ichikawa, "Spatial correlation structures of fracture systems for deriving a scaling law and modeling fracture distributions," Computers and Geosciences, vol. 32, no. 8, pp. 1079-1095, 2006.

[6] K. Koike, S. Nagano, and M. Ohmi, "Lineament analysis of satellite images using a Segment Tracing Algorithm (STA)," Computers and Geosciences, vol. 21, no. 9, pp. 1091-1104, 1995.

[7] H. Jing and Y. C. Shen, "Remote sensing information extraction and analysis of Jiaolai basin north rim," Geology and Prospecting, vol. 5, pp. 91-94, 2001.

[8] Y. B. Zhao, Z. W. He, Z. Y. Ni, H. Q. Chen, and D. H. Zhang, "The correlation study of lineaments and geological disasters in XinPing County, Yunnan province," Chinese Journal of Geological Hazard and Control, vol. 20, pp. 70-73, 2009.

[9] V. Raghavan, S. Masumoto, K. Koike, and S. Nagano, "Automatic lineament extraction from digital images using a segment tracing and rotation transformation approach," Computers and Geosciences, vol. 21, no. 4, pp. 555-591, 1995.

[10] C. Zeeb, E. Gomez-Rivas, P. D. Bons, S. Virgo, and P. Blum, "Fracture network evaluation program (FraNEP): a software for analyzing 2D fracture trace-line maps," Computers and Geosciences, vol. 60, pp. 11-22, 2013.

[11] C. Xu and P. Dowd, "A new computer code for discrete fracture network modelling," Computers and Geosciences, vol. 36, no. 3, pp. 292-301, 2010.

[12] M. Markovaara-Koivisto and E. Laine, "MATLAB script for analyzing and visualizing scanline data," Computers and Geosciences, vol. 40, pp. 185-193, 2012.

[13] H. Bagheri, "Crustal lineament control on mineralization in the Anarak area of Central Iran," Ore Geology Reviews, vol. 66, pp. 293-308, 2015.

[14] F. P. Bierlein, D. I. Groves, and P. A. Cawood, "Metallogeny of accretionary orogens-the connection between lithospheric processes and metal endowment," Ore Geology Reviews, vol. 36, no. 4, pp. 282-292, 2009.

[15] K. Koike, S. Nagano, and K. Kawaba, "Construction and analysis of interpreted fracture planes through combination of satelliteimage derived lineaments and digital elevation model data," Computers and Geosciences, vol. 24, no. 6, pp. 573-583, 1998. 
[16] S. A. Meshkani, B. Mehrabi, A. Yaghubpur, and M. Sadeghi, "Recognition of the regional lineaments of Iran: using geospatial data and their implications for exploration of metallic ore deposits," Ore Geology Reviews, vol. 55, pp. 48-63, 2013.

[17] J. P. Richards, "Lineaments revisited," Society of Economic Geologists Newsletter, vol. 42, pp. 14-20, 2000.

[18] D. X. Qin, S. C. Tan, Z. G. Fan et al., "Geotectonic evolution and tin-polymetallic etallogenesis in GeJiu-DaChang area," Acta Mineralogica Sinica, vol. 241, pp. 117-123, 2004.

[19] Y. Q. Zhuang, R. C. Wang, S. P. Yang, and J. M. Yin, Geology of Gejiu Tin-Copper Polymetallic Deposit, Seismological Press, Beijing, China, 1996 (Chinese).

[20] Y. B. Cheng, J. W. Mao, Z. S. Chang, and F. Pirajno, “The origin of the world class tin-polymetallic deposits in the Gejiu district, SW China: constraints from metal zoning characteristics and ${ }^{40}$ Ar- ${ }^{39}$ Ar geochronology," Ore Geology Reviews, vol. 53, pp. 5062, 2013.

[21] C. Z. Ni, C. X. Liu, and S. T. Zhang, "Estimation of three-dimensional distribution of fissures according to fissure traces on outcrops," Oil \& Gas Geology, vol. 34, no. 1, pp. 102-106, 2013.

[22] B.-L. Li, J.-W. Mao, G.-P. Mo, X.-S. Chen, and D.-Q. Zhu, "An analysis and measurement of joints developed in typical orefields of the Gejiu tin-copper polymetallic ore concentration area, Yunnan Province," Geology in China, vol. 39, no. 6, pp. 1657-1669, 2012.

[23] D. Y. Ma, Y. Tao, Z. M. Gao, H. Zhang, and X. Y. Wu, “Tectonic characteristics of REE and exploration significance in Gejiu tin deposit," Geology and Exploration, vol. 39, pp. 37-38, 2003.

[24] J. Zhao, R. Zuo, S. Chen, and O. P. Kreuzer, "Application of the tectono-geochemistry method to mineral prospectivity mapping: a case study of the Gaosong tin-polymetallic deposit, Gejiu district, SW China," Ore Geology Reviews, vol. 71, pp. 719734, 2015.

[25] S. Y. Sun, "Study on the multi-episodic activity of faults in the gaosong field of gejiu tin deposits," Acta Mineralogica Sinica, vol. 24, pp. 124-128, 2004.

[26] C. X. Liu, C. Z. Ni, Y. F. Yan, and L. Tan, "Automatically extraction of lineaments from DEM," Remote Sensing Technology and Application, vol. 29, pp. 273-277, 2014. 


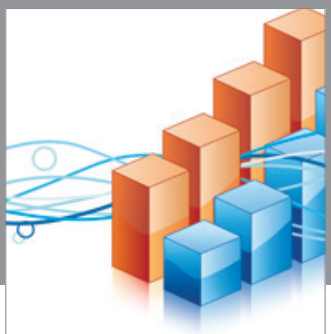

Advances in

Operations Research

vatem alat4

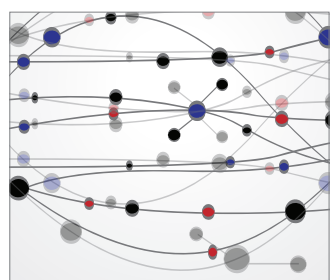

\section{The Scientific} World Journal
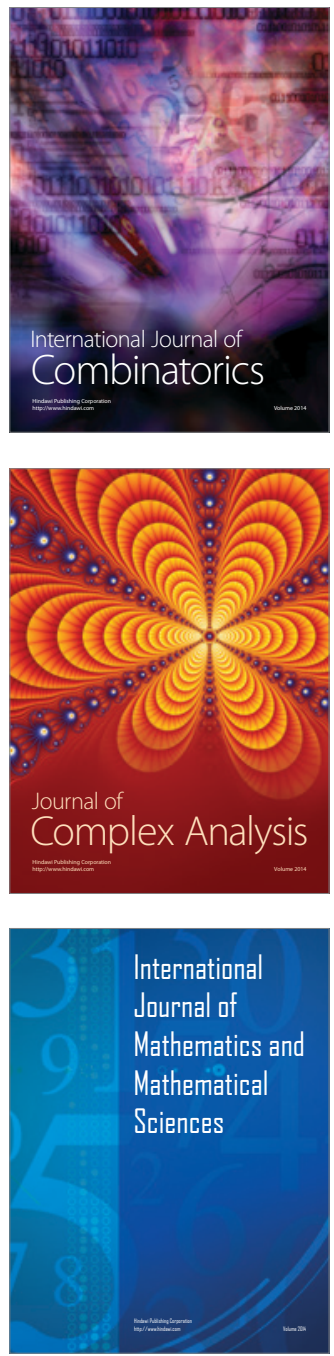
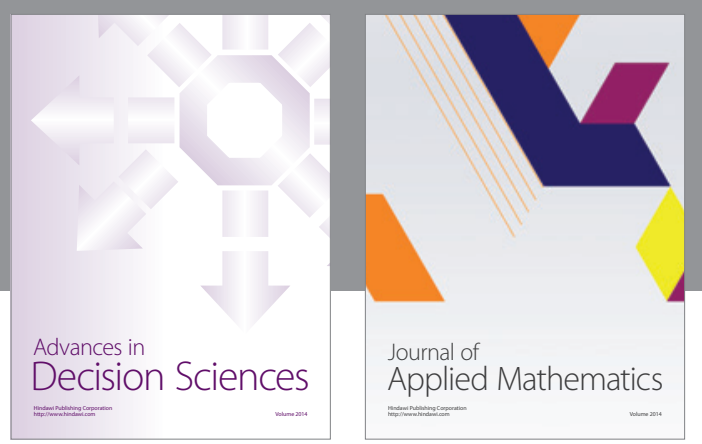

Algebra

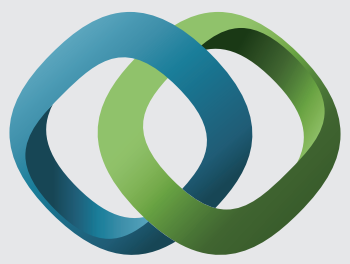

\section{Hindawi}

Submit your manuscripts at

http://www.hindawi.com
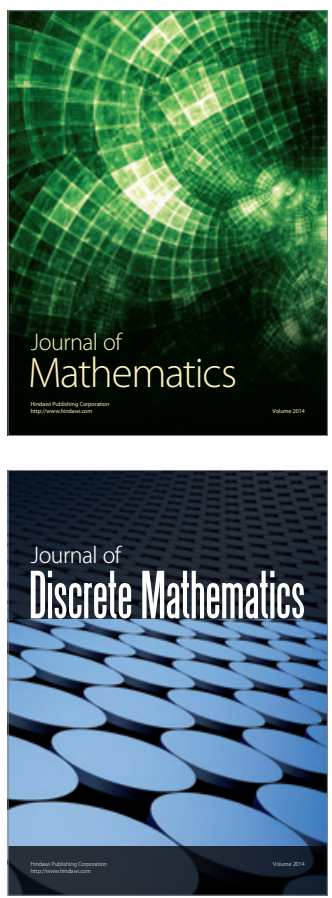

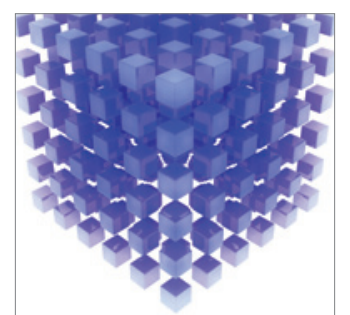

Mathematical Problems in Engineering
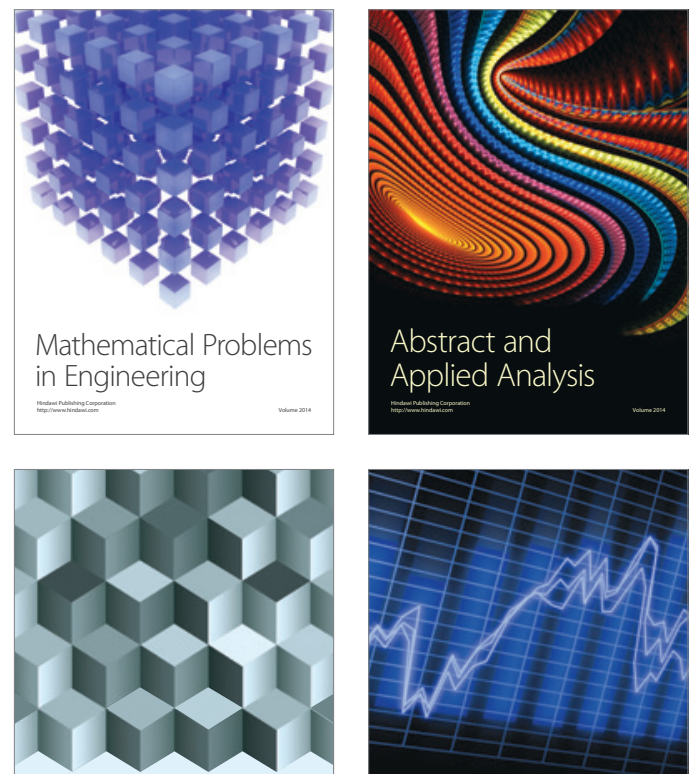

Journal of

Function Spaces

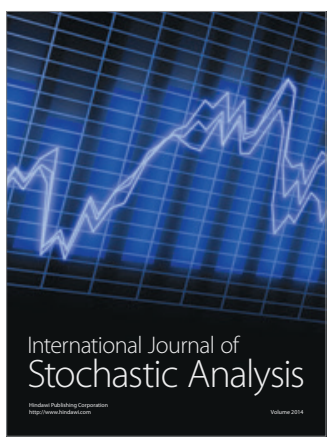

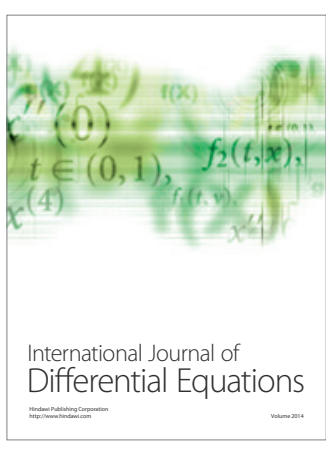
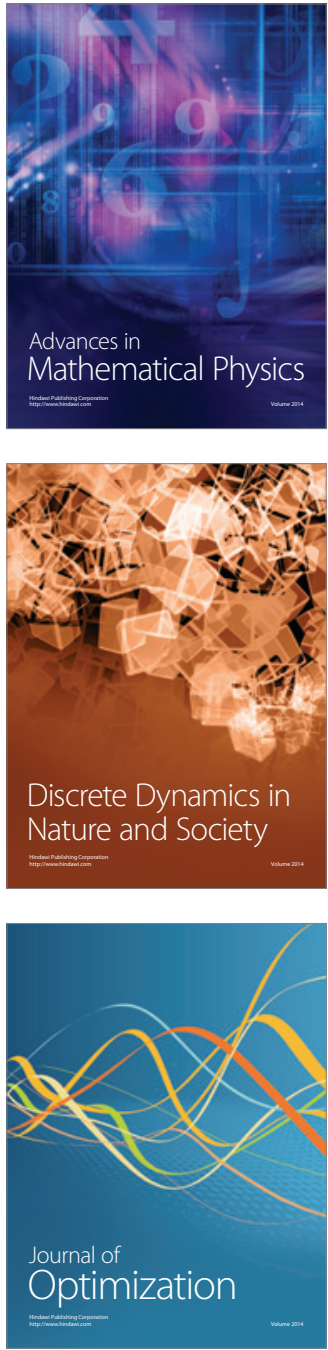